\title{
Solid Dispersion as a Technical Solution to Boost the Dissolution Rate and Bioavailability of Poorly Water-Soluble Drugs
}

\author{
Mohamed Salah Attia*, Azza Ali Hasan, Fakhr-Eldin Soliman Ghazy, Eman Gomaa \\ Department of Pharmaceutics, Faculty of Pharmacy, Zagazig University, Zagazig, EGYPT.
}

\begin{abstract}
Solid dispersion (SD) is one of the oldest and widely utilized techniques to improve the solubility of slowly dissolving drugs. A variety of pharmaceutically compatible additives using different emerging technology is used for preparing SDs. Multiple approaches were designed to prepare SDs by such as kneading, co-milling, fusion, solvent evaporation and various solvent-associated methods. The selection of appropriate preparation method and carrier is vital for producing a homogenous product affecting its stability and biological activity. Many attempts were recently carried out to improve the scalability of the applied approaches and the results were novel preparation methods such as KinetiSol, Electrospinning and Hot-melt extrusion. In the present review, drug carriers used to formulate SD were classified as small molecular weight carriers, large molecular weight named polymeric carriers and functionalized polymeric ones. Moreover, new attractive SD formulated using the newly emerged natural carriers recently joined the field of the pharmaceutical industry.
\end{abstract}

Key words: Solid dispersion, Solvent evaporation, Fusion, Co-milling, Kneading, Electrospinning, KinetiSol ${ }^{\circledR}$.

\section{INTRODUCTION}

Drug delivery via the oral route is the most commonly applied administration method due to its ease of administration, flexible handling, cost-effectiveness, thus increasing good patient compliance. ${ }^{1-3}$ Low bioavailability of poorly water-soluble drugs is considered a frequently occurring limitation for $40 \%$ of the new chemical entities resulting from the low solubility and low dissolution rates of poorly watersoluble drugs in the aqueous gastrointestinal fluids. ${ }^{2}$ The drug dissolution in the gut fluids is the rate-limiting step in determining the bioavailability of the Biopharmaceutical Classification System (BCS) class II of drugs since these drugs are permeated through the gut mucosa. ${ }^{4}$ The dissolution rate and, consequently, bioavailability can be boosted by different techniques, including physical, chemical modifications and inclusion into carrier systems. The technique applied to a drug into a hydrophilic carrier generating more soluble products is called SD. ${ }^{5}$

Considering the SD technology, many researchers have issued various Classification of SD product based on preparation methods and the carrier's nature and generation. Herein, the article tried to concentrate on the most applicable methods with high yield production. A new classification simplified diagrammatically was made to explain the recent updates.

\section{Applied strategies for dissolution rate enhancement}

The adopted strategies to enhance drug solubility and dissolution rate are generally classified into physical and chemical modifications; besides, carriers systems and media modifications are shown in Figure 1., ${ }^{2,5-7}$
Submission Date: 16-03-2021; Revision Date: 29-04-2021; Accepted Date: 16-05-2021

DOI: 10.5530/ijper.55.2s.103 Correspondence: Mr. Mohamed S Attia Department of Pharmaceutics, Faculty of Pharmacy, Zagazig University, Zagazig-44519, EGYPT.

Phone: $+20-1146696987$

Email id: msalahatia@zu.edu. eg

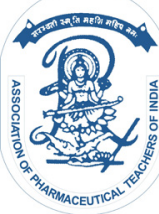

www.ijper.org 
Dissolution enhancement via SD technique is one of the most direct and frequently utilized methods to improve the drug absorption rate into the systemic circulation the systemic circulation. The term solid dispersion refers to those solid products (either amorphous or crystalline) most frequently formed by incorporating a hydrophobic drug into a hydrophilic carrier. ${ }^{8}$ The drug spreads in the chosen polymer resulting in six different types of dispersions that vary according to the molecular arrangement, which affects the properties of the prepared SD. ${ }^{9}$

\section{Advantages and disadvantages of solid dispersions}

SDs have various benefits and drawbacks, as presented in Table 1., ${ }^{510-13}$ Classification of SDs according to the recent advances:

\section{First-generation solid dispersion}

In this type, the dispersion system is formed by drug incorporation into crystalline carriers such as urea and sugars, creating a slowly releasing thermodynamically stable crystalline SD. ${ }^{14-16}$ The eutectic mixture was the first SD to be formulated. The monotectic mixture is not favored since the product and carrier melting points are unaffected. In contrast, the eutectic dispersion has a lower melting point than the carrier and drug melting points. The product and carrier will instantly crystallize during the cooling phase of the eutectic mixture, so it is preferred over the monotectic mixture. ${ }^{15,17}$ The reduced particle size increases the specific surface area, thus enhances the dissolution rate and bioavailability. ${ }^{17}$

\section{Second generation solid dispersion}

This generation contains amorphous carriers and is favored over the first generation for their thermodynamic stability, such as PolyVinyl Pyrrolidone (PVP) and Poly Ethylene Glycol (PEG). ${ }^{15,18}$ Amorphous carriers can be either synthetic or natural polymer. Based on the drug's physical state, amorphous solid dispersion (ASD) can be classified as amorphous solid suspensions, solutions (glass solutions), or a mixture of both. ${ }^{18,19}$ Amorphous solid suspensions consist of two separate phases due to the limited solubility of the dispersed drug in the chosen carrier. ${ }^{20}$ While in the amorphous solid solutions, the ingredients are molecularly dispersed into one homogenous phase. ${ }^{21}$ Upon storage, the drug may recrystallize, producing less dissolving crystals. Although using more viscous polymers can impede the drug dissolution rate, it is often used to tackle the recrystallization drawback providing a more stable formulation suitable for manufacture. ${ }^{17}$

\section{Third generation solid dispersion}

In this generation, the carrier is supposed to have a surface activity or emulsifying activity to tackle drug nucleation and agglomeration. ${ }^{5,16}$ This feature prevents recrystallization while, enhances the dissolution rate, physical and chemical stability of the formulated drug. ${ }^{22}$ Gelucire 44/14 and Solutol HS 15 are two examples of surfactants used to enhance the drug dissolution rate, while polymers of low glass transition temperature $\left(\mathrm{T}_{\mathrm{o}}\right)$ such as poloxamer $\left(\mathrm{P}_{188}\right)$ can inhibit recrystallization. ${ }^{22-24}$

\section{Fourth-generation solid dispersion}

In contrast to ASDs, the fourth generation of dispersions is Controlled Release Solid Dispersions (CRSD). The proposed carriers such as Hydroxy Propyl Cellulose (HPC) and Eudragit RS are used to sustain the release of biologically short half-life drugs. ${ }^{14,25}$ Solubility enhancement and extending the drug release in a controlled manner are the main targets of the CSRD. ${ }^{25}$

\section{Classification of solid dispersion according to the drug dispersion into the carrier}

SDs are classified into six types according to the crystal state of carriers and incorporated drugs, including eutectic mixture, ${ }^{26}$ solid solutions, ${ }^{27}$ glass solutions, ${ }^{28}$ glass suspensions ${ }^{29}$ and amorphous precipitates of the drug in the crystalline carrier ${ }^{11}$ and complex or new compound formation. ${ }^{30}$ According to the molecular size of the drug, the solid solutions system is generally classified as substitutional and interstitial solid solutions. ${ }^{11}$ These

\begin{tabular}{|c|c|}
\hline \multicolumn{2}{|c|}{ Table 1: Advantages and drawbacks of solid } \\
dispersions.
\end{tabular}


classes are illustrated in Figure 2 in which the number of phases physical state of each component is indicated.

\section{Mechanism of drug incorporation and release from solid dispersion}

Theoretically, when drug and polymer are in close contact at the molecular level, the drug molecules are introduced into the gaps within the loosened polymeric chains. Loosening polymer chains is necessary to incorporate the drug molecules, as the effect of heat achieves this flexibility, whether by hot-melt extrusion or fusion method. ${ }^{17}$ Many techniques are based on using solvents, such as solvent evaporation and co-precipitation methods. The used solvent has a dual role: besides converting the drug into a molecular state, the solvent creates weak inter-and intra-molecular cohesion polymer chain interactions, developing polymer interactions with different solvents. ${ }^{8}$

One effective strategy for dissolution enhancement is converting the crystalline form of a poorly soluble drug into an amorphous state. ${ }^{31,32}$ Thus, the drug release mechanism is dependent on the type of the dispersion system, which are different generations of ASD and CRSD.

\section{Drug release from ASD}

The drug release from ASDs is a process that can be classified into three groups according to the drug-carrier release rate into carrier-controlled, drug-controlled and dissolution-controlled release. ${ }^{33}$ In the carrier-controlled release, water penetrates the polymer forming a viscous gel layer, from which the drug is slowly released. While in the case of drug-controlled release, the amorphous drug dissolves at a controlled rate after the polymer is initially dissolved into the dissolution medium.

The dissolution-controlled release is characterized by the simultaneous release of drug and polymer into the dissolution medium, leading to a significant super saturation effect. Here, the polymer in solution is essential to stabilize the supersaturated state. The super saturation concentration is controlled by the drug amount and the volume of the release medium.

\section{Drug release from CSRD}

The fourth-generation solid dispersion release profile shows a controlled dissolution behavior different from the first three generations. In this generation, the CSRD releases the drug into the medium via diffusion- and erosion-based mechanisms as illustrated in Figure 3.

\section{Solid dispersion preparation techniques}

SDs can be prepared through different approaches approaches, including kneading, co-milling, fusion, solvent evaporation and solvent melting techniques. These methods are classified according to their scalability into lab and large-scale techniques, as shown

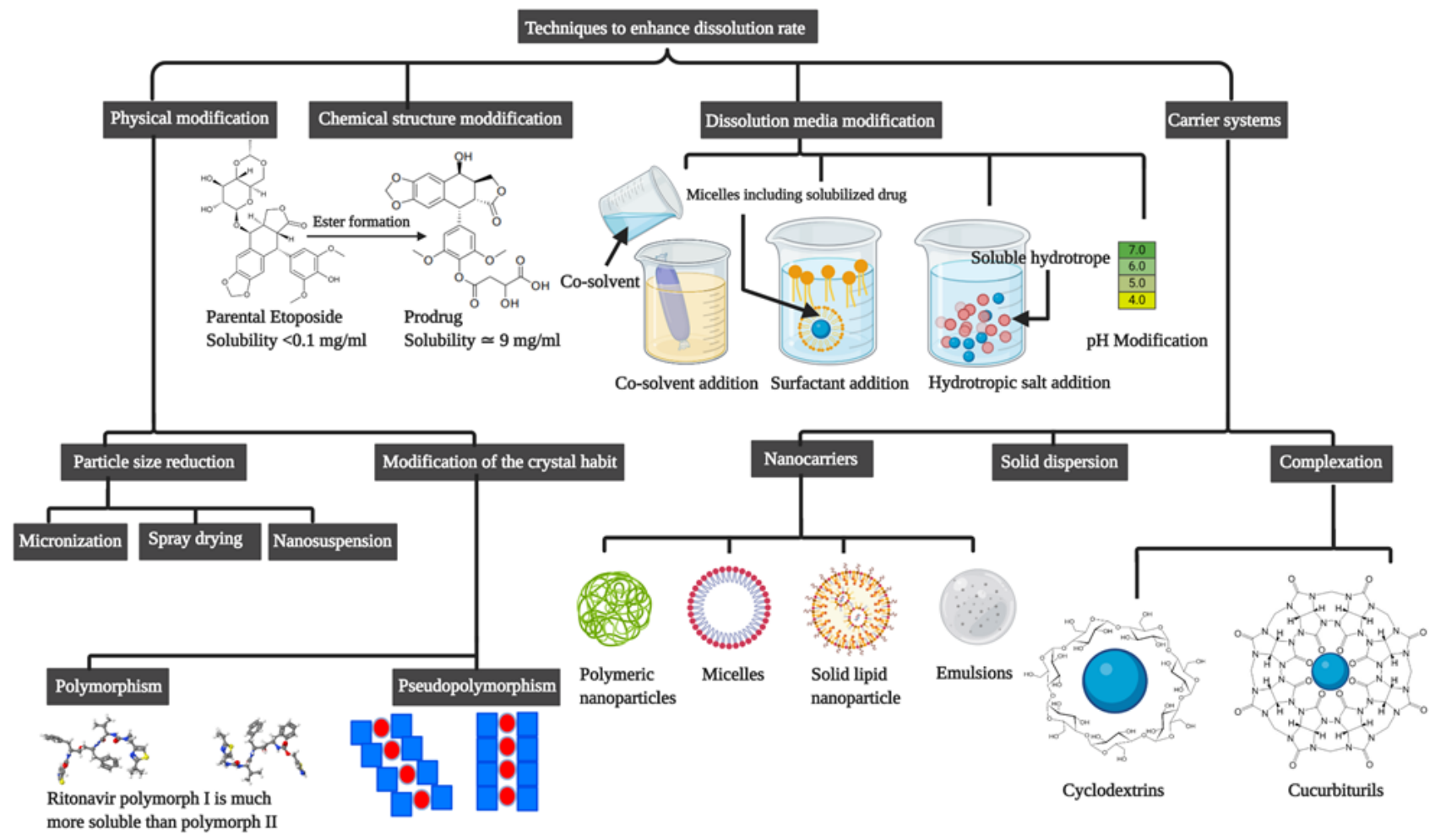

Figure 1: Enhancement strategies for drug solubility and dissolution rate. 
in Figure 4. The application and limitations of these techniques are summarized in Table 2.

\section{Kneading method}

The carrier is co-crushed with the drug forming a dense paste by using a minimal amount of organic solvents such as alcohol, acetone, or water. The incorporated amount of solvent is then extracted via a vacuum oven and the produced mass is ground into a fine powder. ${ }^{34,35}$ The kneading method is cost-effective but challenged by the remaining solvent residuals. ${ }^{36}$

\section{Co-Milling Method}

The method of co-milling is the most straightforward process for SDs preparation. The drug and carrier are co-blended without solvent or heating for hours to produce a homogeneous solid. ${ }^{37}$ This process can also reduce the size of drug particles and transform the substance into an amorphous form. It is assumed that low-temperature tends to produce an amorphous form of the drug, while milling above $\mathrm{Tg}$ can yield crystalline forms. However, its main drawback is forming a heterogeneous mixture with weak drug-polymer interactions and low physical stability. ${ }^{38}$

\section{Hot-Melt Methods (Fusion-Based Method)}

Sekiguchi and Obi first introduced the melting or fusion process to provide a simple and economical preparation method. In this process, the combination of drug and hydrophilic carrier is directly heated until melting. The melted mixture is then rapidly cooled and solidified in an ice bath with strict stirring. The final solid mass is then crushed to reduce the particle size to be incorporated homogeneously in a suitable dosage form. ${ }^{39}$ The melting point of this binary system depends on its composition, carrier selection and the weight fraction of the drug in the system. For example, poloxamer $\left(\mathrm{P}_{188}\right)$ has a low melting point making it a suitable candidate for the fusion method. ${ }^{40,41}$ The fusion method is limited by the thermal stability of the ingredients and their miscibility since some carriers have a melting point above the drug degradation temperature. ${ }^{42}$

The fusion method can be easily applied in laboratories using a conventional or microwave oven. Microwaves with frequencies of $0.3-300 \mathrm{GHz}$ can be applied for the production of SDs. These waves pass through the drug/ carrier mixture, making it oscillate in alignment with the externally applied radiations, thus generating heat enough for fusion. ${ }^{43}$ This method is cost-effective and the heat is generated rapidly and uniformly. ${ }^{36}$

Two large-scale methods have been developed with the concept of fusion technique, including hot-melt extrusion $^{42,44}$ and KinetiSol ${ }^{\circledR} .{ }^{45,46}$

Recently, the technology of using hot twin-screw extruders has provided a suitable choice to solve the scale-up problem of the fusion method. After feeding with the drug/carrier mixture, it is melted, mixed and squeezed between five different temperature zones reaching $185^{\circ} \mathrm{C}$, then extruded through the die in various forms, including pellets, sticks and sheets. ${ }^{47,48}$ Although this method usually uses high temperature and requires

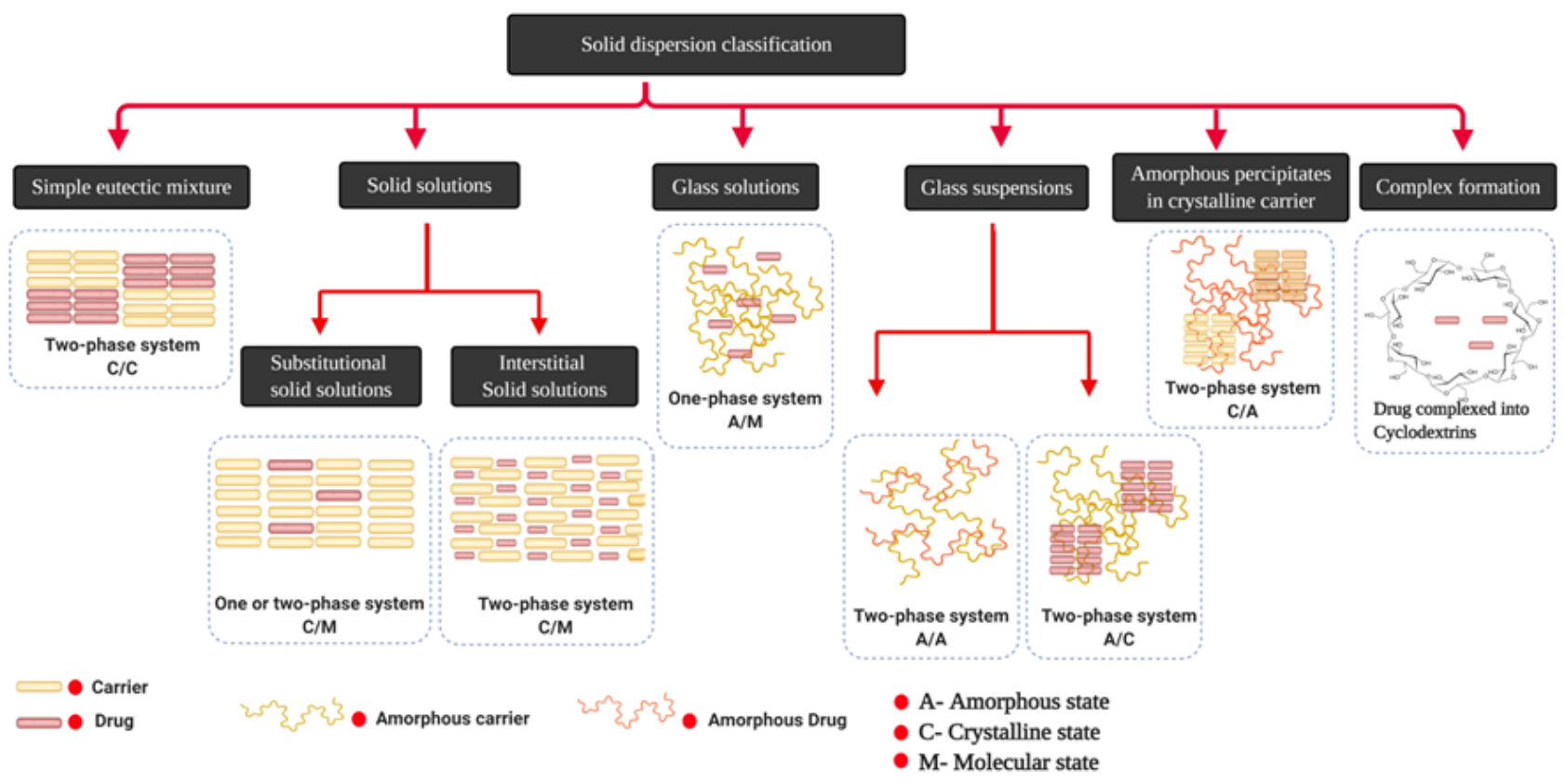

Figure 2: Classification of solid dispersion according to the physical state of the drug and carrier. 
Table 2: Applications of the solid dispersion preparation techniques and their advantages and limitation.

\begin{tabular}{|c|c|c|c|c|}
\hline Method & Carrier/Drug & Advantages & Limitations & Ref \\
\hline 1. Kneading & $\begin{array}{l}\text { Poloxamer } \mathrm{P}_{188} \text { and } \\
\text { 407/Boswellic acid }\end{array}$ & - A simple and economical method. & $\begin{array}{ll}\text { - } & \text { Heterogeneity } \\
\text { - } & \text { Solvent residuals }\end{array}$ & 34,36 \\
\hline $\begin{array}{l}\text { 2. Co-milling } \\
\text { (comminution) }\end{array}$ & $\begin{array}{l}\text { a-Lactose / } \\
\text { Budesonide }\end{array}$ & - A simple and economical method & $\begin{array}{ll}\text { - } & \text { Thermodynamic } \\
\text { instability } \\
\text { - } \\
\text { Alteration of the particle } \\
\text { size distribution }\end{array}$ & 37,38 \\
\hline \multicolumn{2}{|l|}{ 3. Fusion } & - $\quad$ Solvent-free method & $\begin{array}{ll}\text { - } & \text { Require drug/carrier } \\
\text { miscibility } \\
\text { - } & \text { Thermolabile drugs }\end{array}$ & \\
\hline i. Simple fusion & $\begin{array}{c}\text { Urea/Rofecoxib } \\
\text { PEG 4000/Gliclazide }\end{array}$ & - A simple and economical method & $\begin{array}{ll}\text { - } & \text { Phase separation } \\
\text { - } & \text { Scale-up }\end{array}$ & $5,89,90$ \\
\hline $\begin{array}{l}\text { ii. Hot-melt } \\
\text { extrusion }\end{array}$ & Soluplus ${ }^{\circledast / T e l m i s a r t a n}$ & $\begin{array}{l}\text { - } \quad \text { Continuous process suitable for } \\
\text { large scale } \\
\text { - } \quad \text { Short heating time }\end{array}$ & $\begin{array}{ll}\text { - } & \text { Processes at a high temp } \\
\text { - } & \text { High input energy } \\
\text { High shear force }\end{array}$ & $47,91,92$ \\
\hline $\begin{array}{l}\text { iii. Microwave } \\
\text { induced fusion }\end{array}$ & $\begin{array}{l}\text { PEG } 6000 / \\
\text { Atorvastatin }\end{array}$ & $\begin{array}{ll}\text { - } & \text { A rapid, uniform heating } \\
\text { - } & \text { Short heating time } \\
\text { - } & \text { Cost-effective }\end{array}$ & - Scale-up & 36,93 \\
\hline iv. KinetiSol@ & $\begin{array}{l}\text { Polyvinyl alcohol/ } \\
\text { Ritonavir }\end{array}$ & $\begin{array}{l}\text { - } \quad \text { Processes at a lower temp } \\
\text { - } \quad \text { Processing thermolabile drugs } \\
\text { kg/hr. }\end{array}$ & - N/A & $12,42,45$ \\
\hline \multicolumn{2}{|c|}{ 4. Solvent evaporation } & $\begin{array}{ll}\text { - } \quad \text { No heating } & \text { Suitable for thermolabile drugs }\end{array}$ & $\begin{array}{l}\text { - Presence of toxic solvent } \\
\text { residuals and high risk of } \\
\text { phase separation }\end{array}$ & 5 \\
\hline $\begin{array}{l}\text { i. Simple solvent } \\
\text { evaporation }\end{array}$ & $\begin{array}{l}\text { Phospholipid complex } \\
\text { or TPGS } 1000 \text { or } \\
\mathrm{SiO}_{2} / \text { Berberine }\end{array}$ & $\begin{array}{ll}\text { - } & \text { Simple } \\
\text { - } & \text { Suitable for heat-labile ingredients }\end{array}$ & $\begin{array}{ll}\text { - } & \text { High cost } \\
\text { - } & \text { Phase separation } \\
\text { may occur under slow } \\
\text { evaporation condition }\end{array}$ & 94 \\
\hline ii. Spray drying & Mannitol/Diazepam & $\begin{array}{ll}\text { - } & \text { Particle size control } \\
\text { - } & \text { Fair powder flowability } \\
\text { - } & \text { A rapid and economical method } \\
\text { Scale-up. }\end{array}$ & $\begin{array}{l}\text { - Require high solubility of } \\
\text { the drug/carrier mixture } \\
\text { in the organic solvents }\end{array}$ & 54 \\
\hline iii. Lyophilization & $\begin{array}{l}\text { Skimmed milk/ } \\
\text { Simvastatin }\end{array}$ & - Homogeneity & - $\quad$ High cost & 95 \\
\hline $\begin{array}{l}\text { iv. Electrostatic } \\
\text { spinning }\end{array}$ & $\begin{array}{l}\text { PVP VA64/ } \\
\text { Itraconazole }\end{array}$ & - High surface area for evaporation & - $\quad$ Scale-up & 55 \\
\hline v. Fluid-bed coating & PEG 6000/resveratrol & $\begin{array}{ll}\text { - } & \text { Suitable for tableting and } \\
\text { encapsulation } \\
\text { - } & \text { Higher drug loading } \\
\text { - } & \text { Scale-up }\end{array}$ & - Tedious process & 36,80 \\
\hline \multicolumn{5}{|c|}{ 5. Miscellaneous solvent-based methods } \\
\hline i. Solvent-melt & $\begin{array}{l}\text { Polyoxyethylene } 40 \\
\text { stearate/ cyclosporin }\end{array}$ & $\begin{array}{l}\text { - Suitable for thermolabile } \\
\text { components }\end{array}$ & $\begin{array}{l}\text { Applicable for low dose } \\
\text { drug } \\
\text { Solvent traces may exist } \\
\text { in the final product. }\end{array}$ & 85,86 \\
\hline ii. Supercritical $\mathrm{Co}_{2}$ & $\begin{array}{c}\text { PVP K30/ } \\
\text { Carbamazepine }\end{array}$ & $\begin{array}{ll}\text { - } & \text { Solvent-free } \\
\text { - } & \text { Better flowability }\end{array}$ & - Scale-up & 96 \\
\hline iii. Co-precipitation & $\begin{array}{l}\mathrm{CaCO}_{3} / \text { Calcium } \\
\text { carbonate }\end{array}$ & $\begin{array}{ll}\text { - } & \text { Allow using less volatile solvents } \\
\text { - } & \text { Permit reuse of the solvent }\end{array}$ & $\begin{array}{c}\text { Plasticizer effect } \\
\text { Presence of a large amount of } \\
\text { adsorbed water }\end{array}$ & 5,97 \\
\hline
\end{tabular}




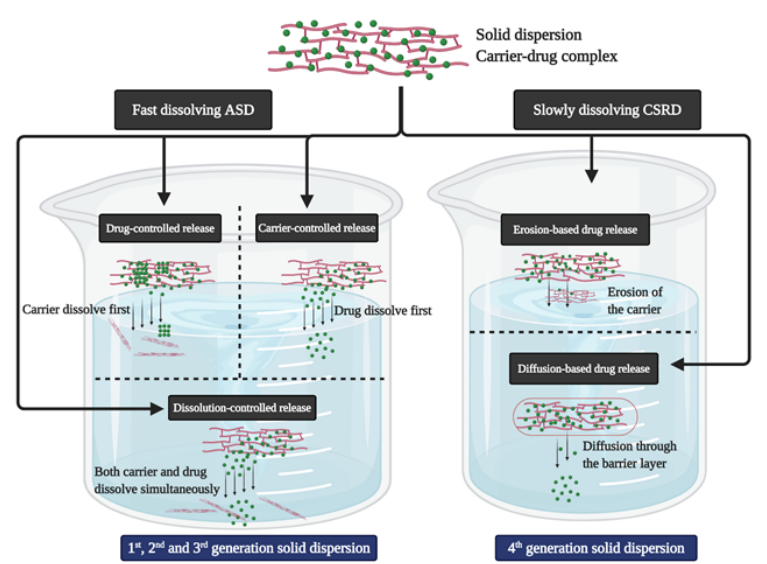

Figure 3: Mechanisms of drug release from a solid dispersion.

high shear force and input energy, the exposure time is too short, approximately one min..$^{36,49,50}$

The method of KinetiSol ${ }^{\circledR}$ was introduced to the field of the pharmaceutical industry as an external heat-free fusion process. In this process, the fusion is based on the frictional forces resulting from exposure to high-speed rotating blades, as shown in Figure 5. The high shear quenching force is enough to melt the mixture without heat application; thus, it is used to prepare ASD in a large scale for heat-labile drugs. ${ }^{51}$

\section{Solvent Evaporation Methods}

Solvent evaporation (SE) methods are available and widely utilized either in small labs or largescale industries. The main procedure involves using a volatile solvent to dissolve the drug and carrier until attaining a homogenous mixture. ${ }^{52}$ After that, to obtain SD, the incorporated amount of solvent is evaporated under different conditions under ambient, heating, or even freezing conditions. The choice of evaporation technique is dependent on the stability of each ingredient. Besides, the surfactant concentration is critical since the evaporation process gradually generates a diffusion layer that can retard drug release. Also, the evaporation speed, the type of solvent or co-solvent and the applied evaporation technique can significantly affect the yield homogeneity; it was reported by $\mathrm{Hu}$ et al. that the homogeneity was much higher when they used a rotary vacuum evaporator. ${ }^{5,53}$

The SE technique is widely employed mainly to overcome drug instability issues when exposed to thermal stress since no or gentle heating is applied in this method. SE can be operated through scale-up techniques with an efficient output, including spray-drying, ${ }^{54}$ freeze-drying, high-speed electrospinning. ${ }^{55}$ While stirring hot plate, rotary evaporation, ${ }^{46}$ Single-needle electrospinning ${ }^{55}$ and lab spray-drying suitable as a small-scale methods.

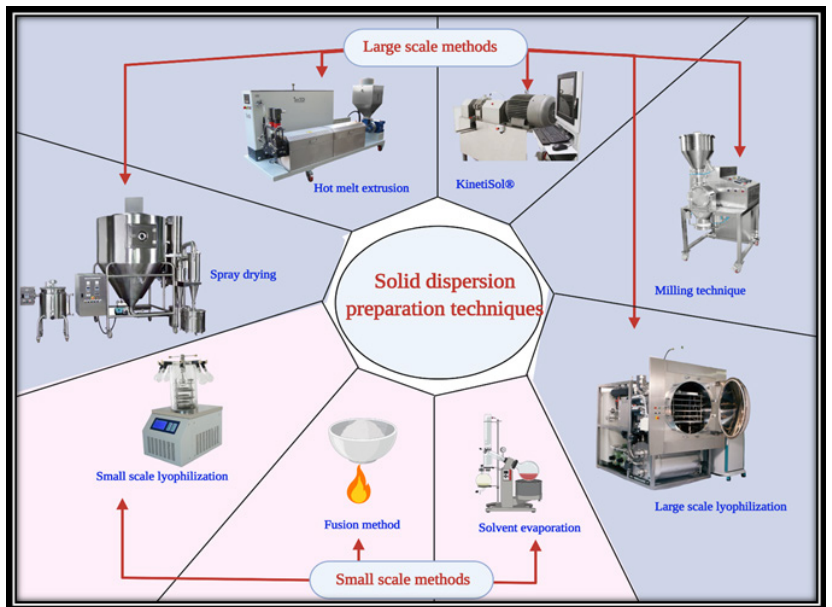

Figure 4: Classification of solid dispersion preparation techniques according to scalability.

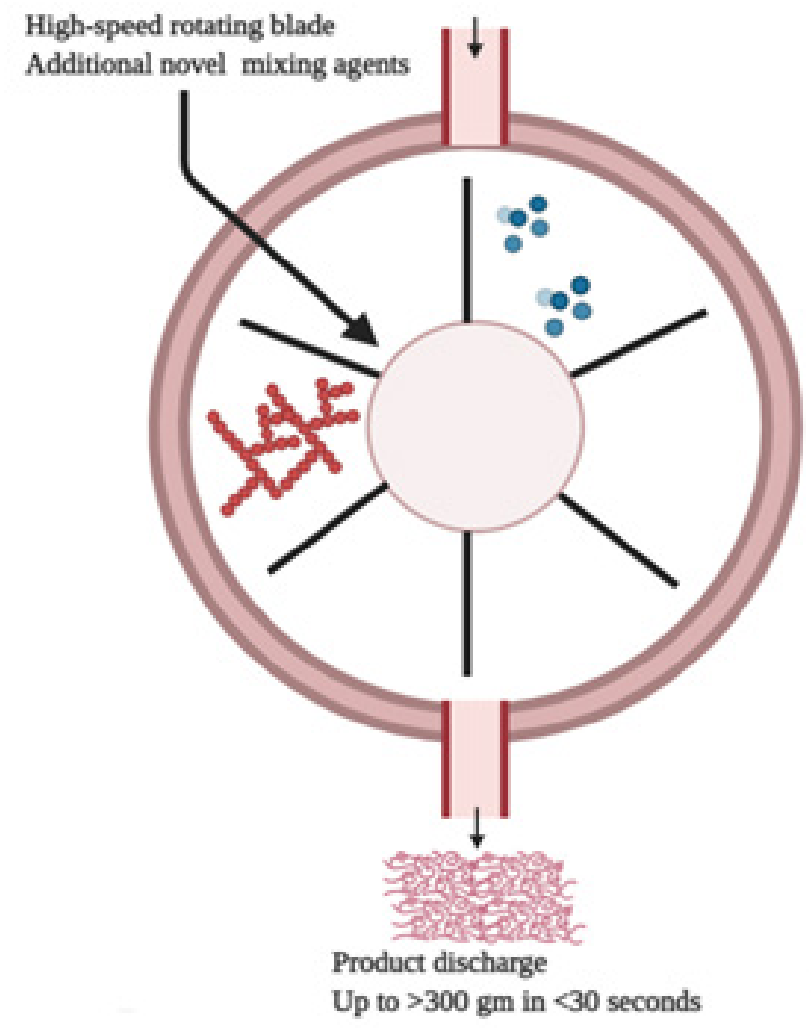

Figure 5: Diagrammatic presentation for the KinetiSol ${ }^{\circledR}$ process.

The high pressure utilized in the spray-drying technique causes evaporation by atomizing the solution via an adjusted diameter nozzle into a drying container. ${ }^{13,56}$ The atomized particles have minimal size and large area, so evaporation becomes faster than typical methods. The quicker the drying process, the more homogenous product obtained since the heterogeneity encountered in common preparation approaches is avoided, yielding reproducible products. Moreover, the atomization 
process controls the particle size of the produced dispersion. Controlling the particle size helps enhance the powder flowability by producing particles in a size range at which they cannot adhere together or produce clumps. ${ }^{57-60}$

The electrostatic spinning process is achieved by charging the polymer solution or melt stream electrostatically under the effect strong electric field. ${ }^{61}$ The applied electrical acceleration and the high surface area provided by this method cause instant evaporation; thus, the product falls out as solid fibers. ${ }^{62,63}$ Several trials were done to merge the electrospinning with other available techniques involving introducing mechanical forces ${ }^{64,65}$ or thermal energy ${ }^{66,67}$ to the conventional electrospinning process. In the electrospinning, the collector has different types, such as in Figure 6 it shows the traditional type of solid collector, while in Figure 7 it presents various types of radial collectors, which can be either rotating mandrel, rotating wire drum, or rotating disk. ${ }^{68,69}$

In this method, the power of the applied electrical field, temperature and flow rate are crucial factors for controlling the product size and shape. ${ }^{70,71}$ As seen in Figure 7 , the electrospinning process is dependent on the polymer concentration since by increasing the polymer in the precursor solution; it starts to form homogenous fibers. In the case of low concentrated solutions, the product is composed of electrosprayed fine powder, then begins to form beads precipitated on fibrous structure with increasing the concentration, then finally forming fibers with the highly concentrated precursors. $^{72,73}$

In the freeze-drying technique, the drug is not exposed to any heating process since it is carried out by immersion under a freezing environment. The applied negative pressure to the solution -usually containing water- is responsible for the subsequent sublimation process. ${ }^{74}$ The lyophilization process can be employed using spray freeze-drying ${ }^{75}$ or ultra-rapid freezing. ${ }^{76,77}$ The lyophilization speed and maintaining the temperature under $\mathrm{Tg}$ of the ingredients during sublimation have a pivotal role in controlling the phase separation. ${ }^{5}$ Thus,

\begin{tabular}{|c|c|c|c|c|}
\hline $\begin{array}{l}\text { Carrier } \\
\text { Class }\end{array}$ & Chemical nature & Pros & Cons & Ref \\
\hline \multirow{3}{*}{ 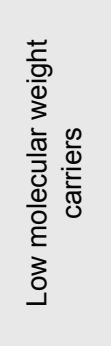 } & $\begin{array}{c}\text { Saccharides } \\
\text { (Sucrose- Glucose - } \\
\text { Lactose) }\end{array}$ & $\begin{array}{l}\text { - Masking the bad taste } \\
\text { (sweetening effect) }\end{array}$ & $\begin{array}{l}\text { - Can compete with drug uptake } \\
\text { - Hereditary problems of intolerance }\end{array}$ & $98-100$ \\
\hline & $\begin{array}{c}\text { Organic acids } \\
\text { (Citric acid - Tartaric acid) }\end{array}$ & $\begin{array}{l}\text { Applicable in preparing } \\
\text { effervescent dispersion }\end{array}$ & - $\quad$ Not practical for acid-sensitive drugs & 101 \\
\hline & $\begin{array}{l}\text { Sugar alcohols } \\
\text { (Mannitol- Sorbitol) }\end{array}$ & $\begin{array}{l}\text { - } \quad \text { Masking the bad taste } \\
\text { Candidate for } \\
\text { chewable tablet }\end{array}$ & $\begin{array}{l}\text { - } \quad \text { Weak drug absorption enhancement } \\
\text { - } \quad \text { Remaitol is not economical } \\
\text { exerting a laxative effect }\end{array}$ & $100,102,103$ \\
\hline \multirow{4}{*}{ 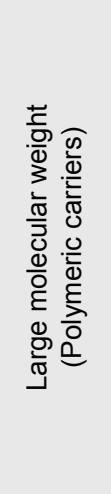 } & $\begin{array}{l}\text { Polyethylene glycols } \\
\text { (PEG } 4000 \text { and 6000) }\end{array}$ & $\begin{array}{ll}\text { - } & \text { Excellent dispersibility } \\
\text { - } & \text { Solubility enhancement } \\
& \text { Recrystallization } \\
& \text { inhibition }\end{array}$ & $\begin{array}{ll}\text { - } & \text { Hygroscopicity } \\
\text { - } & \text { Oxidation and thermal degradation } \\
& \text { upon heating } \\
\text { - } & \text { Potential irritant }\end{array}$ & 104,105 \\
\hline & $\begin{array}{c}\text { Polyvidone } \\
\text { (PVP K15 and K30) }\end{array}$ & $\begin{array}{ll}\text { - } & \text { Excellent dispersibility } \\
\text { - } & \text { Inhibits recrystallization }\end{array}$ & $\begin{array}{ll}\text { - } & \text { High viscosity } \\
\text { - } & \text { Hygroscopicity }\end{array}$ & 106 \\
\hline & $\begin{array}{l}\text { Cellulose derivatives } \\
\text { (HPMC, HPC, and MC) }\end{array}$ & $\begin{array}{l}\text { - } \quad \text { Excellent dispersibility } \\
\text { - } \quad \text { low hygroscopicity. } \\
\text { Inert and safe }\end{array}$ & $\begin{array}{l}\text { - Some grades are of high viscosity with } \\
\text { controlled release properties } \\
\text { - Incompatible with oxidizing agents }\end{array}$ & 107,108 \\
\hline & $\begin{array}{l}\text { Carboxypolymethylene } \\
\text { (Carbopol 907, } 947 \text { and } \\
971)\end{array}$ & $\begin{array}{l}\text { Ionic polymer excellent } \\
\text { for co-percipitation } \\
\text { technique }\end{array}$ & $\begin{array}{l}\text { Some grades are potentially toxic and } \\
\text { irritant } \\
\text { Careful preparation to avoid forming } \\
\text { clumps }\end{array}$ & 105,109 \\
\hline \multirow{2}{*}{ 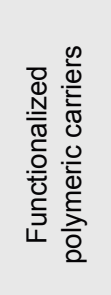 } & $\begin{array}{l}\text { Novel polymeric carrier } \\
\text { (Soluplus } ® \text { ) }\end{array}$ & $\begin{array}{l}\text { Applicable using } \\
\text { hot-melt extrusion } \\
\text { technique }\end{array}$ & $\begin{array}{ll}\text { - } & \text { High viscosity } \\
\text { - } & \text { High-melting point }\end{array}$ & 110 \\
\hline & $\begin{array}{c}\text { Fatty acid } \\
\text { macrogolgycerides } \\
\text { (Gelucire } 44 / 14 \text { and } \\
\text { Gelucire 50/13) }\end{array}$ & $\begin{array}{l}\text { - Suitable for fusion } \\
\text { method } \\
\text { Carrier for oxidizable } \\
\text { and light-sensitive } \\
\text { drugs }\end{array}$ & $\begin{array}{l}\text { - Monolithic Gelucire } 44 / 14 \text { structures } \\
\text { may sustain the drug release }\end{array}$ & $111-113$ \\
\hline
\end{tabular}




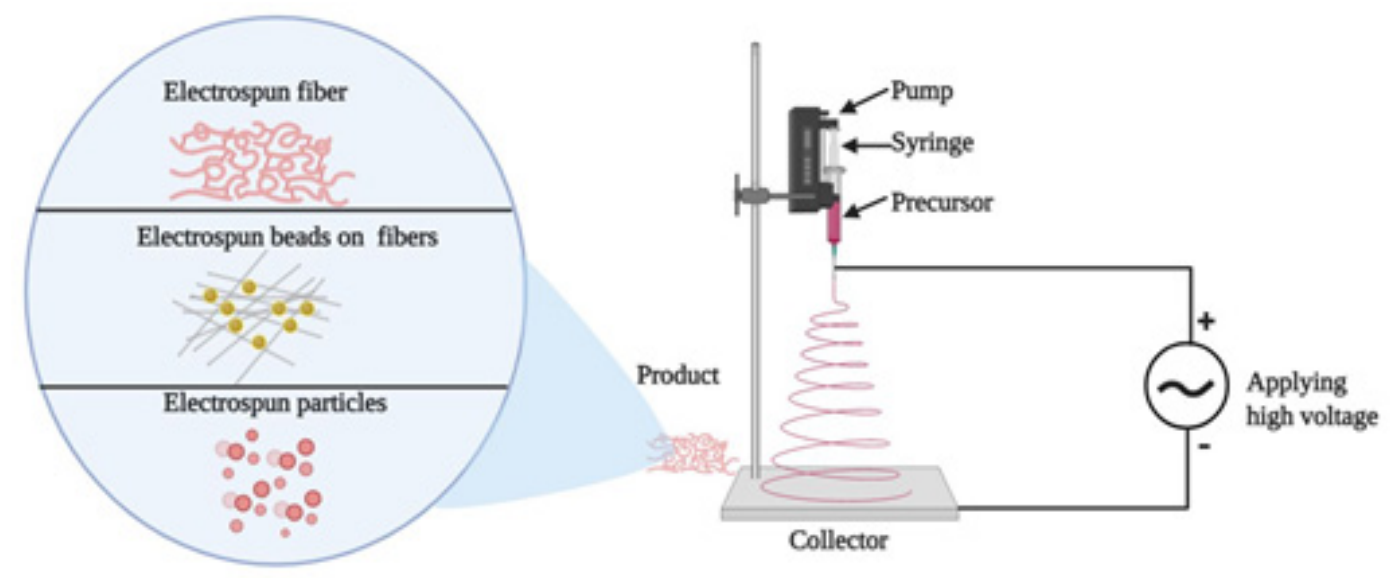

Figure 6: Diagramatic presentation for electrospinning process and the formed product.

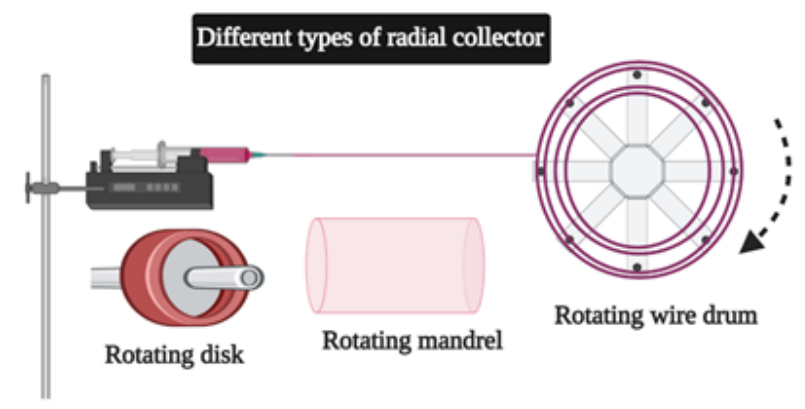

Figure 7: Diagrammatic presentation for the different types of radial collectors.

choosing the technique of freeze-drying is critical in the preparation of stable SD formulation.

The fluid bed coating was recently introduced as an effective technique that involves loading the drug/ carrier mixture on inactive pellets evaporated by flowing air. ${ }^{78,79}$ This method can be industrially employed since it is readily flowable for encapsulation and tableting. ${ }^{80}$

\section{Miscellaneous solvent-based methods}

\section{Co-precipitation technique}

The co-precipitation method is an alternate approach to the SE process using spray dryers, which is based on the concurrent precipitation of the dissolved components by the addition of anti-solvent. ${ }^{81}$ The resulting precipitate is filtered and then washed to prevent the appearance of solvent residuals. To achieve a more homogenous product, simultaneous co-precipitation should be attained. The concurrent precipitation process is more responsive while using ionic polymers with $\mathrm{pH}$-dependent solubilities such as ionic polymers; these polymers are mainly polymethacrylates and carbopols ${ }^{\circledR}$ products.

\section{Supercritical fluids}

Carbon dioxide $\left(\mathrm{CO}_{2}\right)$ was often documented as an alternative to the common solvents. Carbon dioxide

Table 4: Examples of natural carriers and their preparation methods.

\begin{tabular}{|c|c|c|c|}
\hline Natural carrier & Drug & Preparation method & Reference \\
\hline Alginate & $\begin{array}{c}\text { Lovastatin \& } \\
\text { Indomethacin }\end{array}$ & Solvent evaporation & 114 \\
\cline { 2 - 4 } & Tanshinone IIA & $\begin{array}{c}\text { Co-precipitation } \\
\text { (Alcohol precipitation process) }\end{array}$ & 115 \\
\hline $\begin{array}{c}\text { Low molecular } \\
\text { weight Chitosan }\end{array}$ & Indomethacin & Kneading & 116 \\
\hline Skimmed milk & Simvastatin & Lyophilization & 95 \\
\cline { 2 - 4 } & Meloxicam & Rotary vacuum evaporation & 117 \\
\hline Neem gum & Atorvastatin & $\begin{array}{c}\text { Solvent evaporation and } \\
\text { kneading }\end{array}$ & 118 \\
\cline { 2 - 4 } & Aceclofenac & $\begin{array}{c}\text { Solvent evaporation and co- } \\
\text { milling }\end{array}$ & 119 \\
\hline $\begin{array}{c}\text { Tamarind seed } \\
\text { polysaccharide }\end{array}$ & Celecoxib & $\begin{array}{c}\text { Kneading and Co-milling } \\
\text { Noly }\end{array}$ & 120 \\
\hline
\end{tabular}


as a supercritical fluid is desirable since it combines the high diffusivity and low viscosity of the gas and liquid density. ${ }^{82}$ Initially, the drug/carrier mixture is solubilized in the supercritical $\mathrm{CO}_{2}$ and sprayed via a nozzle into the expansion vessel. The sprayed particles are rapidly forming SD of the target size. When $\mathrm{CO}_{2}$ is used as an anti-solvent, the drug/carrier mixture is introduced in an organic solvent. After expelling the mixture into the vessel, the organic solvent is rapidly removed by supercritical $\mathrm{CO}_{2}$, forming $\mathrm{SD}$ particles. ${ }^{83,84}$

\section{Melting-Solvent Evaporation Methods}

This method is a combined approach involving fusion and SE techniques. Once the drug solution is prepared, it is then added to the carrier in a molten state with gentle mixing forming a homogenous mixture. After that, the solvent is evaporated at a lower temperature to obtain a consistent solid product. 85,86

\section{Carriers in solid dispersion}

Carriers used to produce SDs have a pivotal role in controlling the drug release since they can enhance or retard the drug dissolution, whether achieved through diffusion or dissolution-based mechanism, as previously mentioned. . $^{17,25,87}$

A drug carrier should have fair solubility in various solvents, specifically in water and lacking toxicological and pharmacological effects. Chemically, the carrier should have thermal stability and compatibility with the formulated drug. ${ }^{17}$

Carriers are classified according to their molecular weight into low molecular weight and polymeric carriers of high molecular weight, in addition to the functionalized polymeric carriers, as shown in Table 3.

Recently, carriers derived from natural origin have gained great interest and became favorable over synthetic carriers because they are biocompatible, available, chemically inert and biodegradable. ${ }^{17}$ Natural carriers that has enhanced the dissolution rate and bioavailability of model drugs were presented in Table 4.

However, many limitations have been accompanied by natural carriers' use, including the uncontrolled hydration rate, viscosity changes and microbial contamination. The first limitation can be overcome chemically by carboxymethylation or carbomoylethylation of active carboxyl or hydroxyl group resulting in increased water solubility. Also, the latter limitations can be physically treated through dry heating. ${ }^{17,88}$

\section{ACKNOWLEDGEMENT}

We would like to express our appreciation to Dr. Tarek Metwally Ibrahim (Zagazig University) for proofreading this review article. Authors are thankful for BioRender for making figures.

\section{CONFLICT OF INTEREST}

The authors declare no conflict of interest.

\section{ABBREVIATIONS}

SD: Solid Dispersion; SE: Solvent Evaporation; BCS: Biopharmaceutical Classification System; PVP: PolyVinyl Pyrollidine; PEG: Poly Ethylene Glycol; HPC: Hydroxy Propyl Cellulose; MC: Methyl Cellulose; HPMC: Hydroxy Propyl Methyl Cellulose; $\mathbf{T}_{\mathrm{g}}$ : Transition glass temperature; ASD: Amorphous Solid Dispersion; CRSD: Controlled Release Solid Dispersions; FDT: Fast dissolving tablet.

\section{REFERENCES}

1. Bobe K, Subrahmanya C, Suresh S, et al. Formulation and evaluation of solid dispersion of atorvastatin with various carriers. Int $\mathrm{J}$ Compr Pharm. 2011;2(1):1-6.

2. Savjani KT, Gajjar AK, Savjani JK. Drug solubility: Importance and enhancement techniques. ISRN Pharm. 2012.

3. Zhang J, Xie Z, Zhang $\mathrm{N}$, et al. Nanosuspension drug delivery system: preparation, characterization, postproduction processing, dosage form, and application. In: Nanostructures for Drug Delivery. Elsevier. 2017;413-43.

4. Ahuja N, Katare OP, Singh B. Studies on dissolution enhancement and mathematical modeling of drug release of a poorly water-soluble drug using water-soluble carriers. Eur J Pharm Biopharm. 2007;65(1):26-38.

5. Hallouard F, Mehenni L, Lahiani-Skiba M, et al. Solid dispersions for oral administration: An overview of the methods for their preparation. Curr Pharm Des. 2016;22(32):4942-58.

6. Bauer J, Spanton S, Henry R, et al. Ritonavir: An extraordinary example of onformational polymorphism. Pharm Res. 2001;18(6):859-66.

7. Chen J, Du W. Synthesis and Evaluation of Water-Soluble Etoposide Esters of Malic Acid as Prodrugs. Med Chem. 2013;9(5):740-7.

8. Teja SB, Patil SP, Shete G, et al. Drug-excipient behavior in polymeric amorphous solid dispersions. J Excip Food Chem. 2016;4(3):1048.

9. Arunachalam A, Karthikeyan M, Konam K, et al. Solid dispersions: A review. J Curr Pharma Res. 2010;1(1):82.

10. Dhirendra K, Lewis S, Udupa N, et al. Solid dispersions: A review. Pak J Pharm Sci. 2009;22(2).

11. Paudwal G, Rawat N, Gupta R, et al. Recent advances in solid dispersion technology for efficient delivery of poorly water-soluble drugs. Curr Pharm Des. 2019;25(13):1524-35.

12. Zhang $\mathrm{X}$, Xing $\mathrm{H}$, Zhao $\mathrm{Y}$, et al. Pharmaceutical Dispersion Techniques for Dissolution and Bioavailability Enhancement of Poorly Water-Soluble Drugs. Pharmaceutics. 2018;10(3):74.

13. Paudel A, Worku ZA, Meeus J, et al. Manufacturing of solid dispersions of poorly water soluble drugs by spray drying: Formulation and process considerations. Int J Pharm. 2013;453(1):253-84.

14. El-Baz FK, Aly HF, Abd-Alla HI, et al. Therapeutic impact of berries (Morus alba and Morus rubra) fruit extract in the regression of high-fat-diet-induced cardiac dysfunction in rats. Asian J Pharm Clin Res. 2018;11:314-20.

15. Kim KT, Lee JY, Lee MY, et al. Solid dispersions as a drug delivery system. J Pharm Investig. 2011;41(3):125-42.

16. Vasconcelos $\mathrm{T}$, Sarmento B, Costa P. Solid dispersions as strategy to improve oral bioavailability of poor water soluble drugs. Drug Discov Today. 2007;12(23-24):1068-75. 
17. Tekade AR, Yadav JN. A Review on Solid Dispersion and Carriers Used Therein for Solubility Enhancement of Poorly Water Soluble Drugs. Adv Pharm Bull. 2020;10(3):359-69.

18. Saffoon N, Uddin R, Huda NH, et al. Enhancement of oral bioavailability and solid dispersion: a review. J Appl Pharm Sci. 2011;1(7):13-20.

19. Drooge VD, Hinrichs W, Visser $M$, et al. Characterization of the molecular distribution of drugs in glassy solid dispersions at the nano-meter scale, using differential scanning calorimetry and gravimetric water vapour sorption techniques. Int J Pharm. 2006;310(1-2):220-9.

20. Martínez LM, Videa M, Silva TL, et al. Two-phase amorphous-amorphous solid drug dispersion with enhanced stability, solubility and bioavailability resulting from ultrasonic dispersion of an immiscible system. Eur J Pharm Biopharm. 2017;119:243-52.

21. Sheng G, Liu CT. Phase stability in high entropy alloys: Formation of solidsolution phase or amorphous phase. Prog Nat Sci Mater Int. 2011;21(6):43346.

22. Swain R, Subudhi B, Ramesh P. Effect of Solutol HS 15 in Solid Dispersions of Pioglitazone Hydrochloride: In vitro and in vivo Evaluation. Indian J Pharm Sci. 2019;81(2):317-25.

23. Damian F, Blaton N, Naesens L, et al. Physicochemical characterization of solid dispersions of the antiviral agent UC-781 with polyethylene glycol 6000 and Gelucire 44/14. Eur J Pharm Sci. 2000;10(4):311-22.

24. Passerini N, Albertini B, González-Rodríguez ML, et al. Preparation and characterisation of ibuprofen-poloxamer 188 granules obtained by melt granulation. Eur J Pharm Sci. 2002;15(1):71-8.

25. Vo CLN, Park C, Lee BJ. Current trends and future perspectives of solid dispersions containing poorly water-soluble drugs. Eur J Pharm Biopharm. 2013;85(3):799-813.

26. Park H, Seo HJ, Ha ES, et al. Preparation and characterization of glimepiride eutectic mixture with L-arginine for improvement of dissolution rate. Int $\mathrm{J}$ Pharm. 2020;581:119288.

27. Mir KB, Khan NA. Solid dispersion: Overview of the technology. Int J Pharm Sci Res. 2017;8(6):2378-87.

28. Doreth $\mathrm{M}$, Löbmann $\mathrm{K}$, Grohganz $\mathrm{H}$, et al. Glass solution formation in water in situ amorphization of naproxen and ibuprofen with Eudragit@ E PO. J Drug Deliv Sci Technol. 2016;34:32-40.

29. Tran P, Pyo YC, Kim DH, et al. Overview of the manufacturing methods of solid dispersion technology for improving the solubility of poorly water-soluble drugs and application to anticancer drugs. Pharmaceutics. 2019;11(3):132.

30. Boakye-Yiadom KO, Kesse S, Aquib M, et al. Solid dispersion systems engineered from hydroxypropyl- $\beta$-cyclodextrin and water-soluble polymers for enhanced oral bioavailability of nimodipine. Polym Adv Technol. 2020;31(10):2270-8.

31. Allesø $\mathrm{M}$, Chieng $\mathrm{N}$, Rehder $\mathrm{S}$, et al. Enhanced dissolution rate and synchronized release of drugs in binary systems through formulation: Amorphous naproxen-cimetidine mixtures prepared by mechanical activation. J Controlled Release. 2009;136(1):45-53.

32. Kanaujia P, Poovizhi P, $\mathrm{Ng} \mathrm{W}$, et al. Amorphous formulations for dissolution and bioavailability enhancement of poorly soluble APIs. Powder Technol. 2015;285:2-15.

33. Schittny A, Huwyler J, Puchkov M. Mechanisms of increased bioavailability through amorphous solid dispersions: A review. Drug Deliv. 2020;27(1):11027.

34. Tambe A, Pandita N. Enhanced solubility and drug release profile of boswellic acid using a poloxamer-based solid dispersion technique. J Drug Deliv Sci Technol. 2018;44:172-80.

35. Ghareeb MM, Abdulrasool AA, Hussein AA, et al. Kneading technique for preparation of binary solid dispersion of meloxicam with poloxamer 188. Aaps Pharmscitech. 2009;10(4):1206-15.

36. Alam MA, Ali R, Al-Jenoobi Fl, et al. Solid dispersions: A strategy for poorly aqueous soluble drugs and technology updates. Expert Opin Drug Deliv. 2012;9(11):1419-40.

37. Dudognon E, Willart J, Caron V, et al. Formation of budesonide/a-lactose glass solutions by ball-milling. Solid State Commun. 2006;138(2):68-71.

38. Loh ZH, Samanta AK, Sia Heng PW. Overview of milling techniques for improving the solubility of poorly water-soluble drugs. Asian J Pharm Sci. 2015;10(4):255-74.
39. Rathore DS, Thakur RR, Narwal S. Solid Dispersion: A New Horizen in Novel Drug Delivery System. Chemlnform. 2013;44(27):no.

40. Panda T, Das D, Panigrahi L. Formulation development of solid dispersions of bosentan using Gelucire 50/13 and Poloxamer 188. J Appl Pharm Sci. 2016;6:027-33.

41. Sruti J, Patra $\mathrm{CN}$, Swain S, et al. Improvement in dissolution rate of cefuroxime axetil by using poloxamer 188 and Neusilin US2. Indian J Pharm Sci. 2013;75(1):67.

42. DiNunzio JC, Brough C, Hughey JR, et al. Fusion production of solid dispersions containing a heat-sensitive active ingredient by hot melt extrusion and Kinetisol@ dispersing. Eur J Pharm Biopharm. 2010;74(2):340-51.

43. Patil PH, Belgamwar VS, Patil PR, et al. Enhancement of solubility and dissolution rate of poorly water soluble raloxifene using microwave induced fusion method. Braz J Pharm Sci. 2013;49(3):571-8.

44. He H, Yang R, Tang $X$. In vitro and in vivo evaluation of fenofibrate solid dispersion prepared by hot-melt extrusion. Drug Dev Ind Pharm. 2010;36(6):681-7.

45. LaFountaine JS, Jermain SV, Prasad LK, et al. Enabling thermal processing

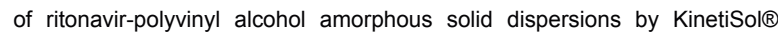
Dispersing. Eur J Pharm Biopharm. 2016;101:72-81.

46. Bennett RC, Brough C, Miller DA, et al. Preparation of amorphous solid dispersions by rotary evaporation and KinetiSol dispersing: Approaches to enhance solubility of a poorly water-soluble gum extract. Drug Dev Ind Pharm. 2015;41(3):382-97.

47. Karanth H, Shenoy VS, Murthy RR. Industrially feasible alternative approaches in the manufacture of solid dispersions: A technical report. Aaps Pharmscitech. 2006;7(4):E31-8.

48. Chokshi R, Zia H. Hot-melt extrusion technique: A review. Iran J Pharm Sci. 2004;3(1):3-16.

49. Huang S, O'Donnell KP, Vaux DSMD, et al. Processing thermally labile drugs by hot-melt extrusion: The lesson with gliclazide. Eur J Pharm Biopharm. 2017;119:56-67.

50. Patil A, Shinkar D, Saudagar R. Review article: Solubility enhancement by solid dispersion. Int J Curr Pharm Res. 2017;9(3):15-8.

51. Hughey JR, DiNunzio JC, Bennett RC, et al. Dissolution enhancement of a drug exhibiting thermal and acidic decomposition characteristics by fusion processing: A comparative study of hot melt extrusion and KinetiSol 8 dispersing. AAPs Pharmscitech. 2010;11(2):760-74.

52. Leuner C, Dressman J. Improving drug solubility for oral delivery using solid dispersions. Eur J Pharm Biopharm. 2000;50(1):47-60.

53. Hu XY, Lou H, Hageman MJ. Preparation of lapatinib ditosylate solid dispersions using solvent rotary evaporation and hot melt extrusion for solubility and dissolution enhancement. Int J Pharm. 2018;552(1-2):154-63.

54. Kauppinen A, Broekhuis J, Grasmeijer N, et al. Efficient production of solid dispersions by spray drying solutions of high solid content using a 3-fluid nozzle. Eur J Pharm Biopharm. 2018;123:50-8.

55. Nagy ZK, Balogh A, Démuth B, et al. High speed electrospinning for scaledup production of amorphous solid dispersion of itraconazole. Int $\mathrm{J}$ Pharm. 2015;480(1-2):137-42.

56. Lim H-T, Balakrishnan $\mathrm{P}, \mathrm{Oh} \mathrm{DH}$, et al. Development of novel sibutramine base-loaded solid dispersion with gelatin and HPMC: Physicochemical characterization and pharmacokinetics in beagle dogs. Int $\mathrm{J}$ Pharm. 2010;397(1-2):225-30.

57. Cerra B, Mosca G, Ricci M, et al. Flow nanoprecipitation of size-controlled d-leucine nanoparticles for spray-drying formulations. React Chem Eng. 2019;4(10):1861-8.

58. Davis MT, Potter CB, Walker GM. Downstream processing of a ternary amorphous solid dispersion: The impacts of spray drying and hot melt extrusion on powder flow, compression and dissolution. Int $\mathrm{J}$ Pharm. 2018;544(1):242-53.

59. Ghanbarzadeh $\mathrm{S}$, Valizadeh $\mathrm{H}$, Yaqoubi $\mathrm{S}$, et al. Application of spray drying technique for flowability enhancement of divalproex sodium. Drug Res. 2018;68(03):168-73.

60. Sarrate R, Ticó JR, Miñarro M, et al. Modification of the morphology and particle size of pharmaceutical excipients by spray drying technique. Powder Technol. 2015;270:244-55.

61. Munir MW, Ali U. Classification of electrospinning methods. In: Nanorods and Nanocomposites. IntechOpen. 2020;229. 
62. Shin YMM, Brenner MP, Rutiedge GC. Experimental Characterization of Electrospinning: The Electrically Forced Jet and Instabilities. Polymer. 2001;42(25):9955-67.

63. Kumar PS, Sundaramurthy J, Sundarrajan S, et al. Hierarchical electrospun nanofibers for energy harvesting, production and environmental remediation. Energy Environ Sci. 2014;7(10):3192-222.

64. Sarkar K, Gomez C, Zambrano S, et al. Electrospinning to forcespinning TM. Mater Today. 2010;13:12-4.

65. Chang WM, Wang CC, Chen CY. The combination of electrospinning and forcespinning: Effects on a viscoelastic jet and a single nanofiber. Chem Eng J. 2014;244:540-51.

66. Lin Y, Clark DM, Yu X, et al. Mechanical properties of polymer nanofibers revealed by interaction with streams of air. Polymer. 2012;53(3):782-90.

67. Zhmayev E, Cho D, Joo YL. Nanofibers from gas-assisted polymer melt electrospinning. Polymer. 2010;51(18):4140-4.

68. Sun Y, Cheng S, Lu W, et al. Electrospun fibers and their application in drug controlled release, biological dressings, tissue repair, and enzyme immobilization. RSC Adv. 2019;9(44):25712-29.

69. Ulubayram K, Calamak S, Shahbazi R, et al. Nanofibers based antibacterial drug design, delivery and applications. Curr Pharm Des. 2015;21(15):193043.

70. Yu DG, Li JJ, Williams GR, et al. Electrospun amorphous solid dispersions of poorly water-soluble drugs: A review. J Controlled Release. 2018;292:91-110.

71. Unnithan AR, Arathyram R, Kim CS. Electrospinning of Polymers for Tissue Engineering. In: Nanotechnology Applications for Tissue Engineering. Elsevier. 2015;45-55.

72. Yu DG, Li JJ, Williams GR, et al. Electrospun amorphous solid dispersions of poorly water-soluble drugs: A review. J Controlled Release. 2018;292:91-110.

73. Alharbi AR, Alarifi IM, Khan WS, et al. Highly hydrophilic electrospun polyacrylonitrile/polyvinypyrrolidone nanofibers incorporated with gentamicin as filter medium for dam water and wastewater treatment. J Membr Sep Technol. 2016;5(2):38-56.

74. Fitriani L, Afriyanti I, Ismed F, et al. Solid Dispersion of Usnic acid-HPMC 2910 Prepared by Spray drying and Freeze drying Techniques. Orient J Chem. 2018;34(4):2083-8.

75. Tong HH, Du Z, Wang GN, et al. Spray freeze drying with polyvinylpyrrolidone and sodium caprate for improved dissolution and oral bioavailability of oleanolic acid, a BCS Class IV compound. Int J Pharm. 2011;404(1-2):14858.

76. Overhoff KA, Moreno A, Miller DA, et al. Solid dispersions of itraconazole and enteric polymers made by ultra-rapid freezing. Int J Pharm. 2007;336(1):12232.

77. Purvis T, Mattucci ME, Crisp MT, et al. Rapidly dissolving repaglinide powders produced by the ultra-rapid freezing process. AAPS Pharm Sci Tech. 2007;8(3):E52-60.

78. Mendonsa N, Almutairy B, Kallakunta VR, et al. Manufacturing strategies to develop amorphous solid dispersions: An overview. J Drug Deliv Sci Technol. 2020;55:101459.

79. Sun N, Wei X, Wu B, et al. Enhanced dissolution of silymarin/ polyvinylpyrrolidone solid dispersion pellets prepared by a one-step fluid-bed coating technique. Powder Technol. 2008;182(1):72-80.

80. Li J, Miao X, Chen T, et al. Preparation and characterization of pelletized solid dispersion of resveratrol with mesoporous silica microparticles to improve dissolution by fluid-bed coating techniques. Asian J Pharm Sci. 2016;11(4):528-35.

81. Mann AK, Schenck L, Koynov A, et al. Producing amorphous solid dispersions via co-precipitation and spray drying: Impact to physicochemical and biopharmaceutical properties. J Pharm Sci. 2018;107(1):183-91.

82. Kohli R. Applications of supercritical carbon dioxide for removal of surface contaminants. In: Developments in surface contamination and cleaning: Applications of cleaning techniques. Elsevier. 2019;209-49.

83. Alshehri S, Imam SS, Hussain A, et al. Potential of solid dispersions to enhance solubility, bioavailability, and therapeutic efficacy of poorly watersoluble drugs: newer formulation techniques, current marketed scenario and patents. Drug Deliv. 2020;27(1):1625-43.

84. Won DH, Kim MS, Lee S, et al. Improved physicochemical characteristics of felodipine solid dispersion particles by supercritical anti-solvent precipitation process. Int J Pharm. 2005;301(1-2):199-208.
85. Chiou WL, Riegelman S. Pharmaceutical applications of solid dispersion systems. J Pharm Sci. 1971;60(9):1281-302.

86. Liu C, Wu J, Shi B, et al. Enhancing the bioavailability of cyclosporine a using solid dispersion containing polyoxyethylene (40) stearate. Drug Dev Ind Pharm. 2006;32(1):115-23.

87. Shahi S, Khan A, Bhalerao P, et al. A review on formulation aspects of solid dispersions. Eur J Pharm Med Res. 2017;4(12):148-60.

88. Prajapati VD, Jani GK, Moradiya NG, et al. Pharmaceutical applications of various natural gums, mucilages and their modified forms. Carbohydr Polym. 2013;92(2):1685-99.

89. Patil MP, Gaikwad NJ. Priprava i karakterizacija gliklazid-polietilen glikol 4000 čvrstih disperzija. Acta Pharm. 2009;59(1):57-65.

90. Liu C, Desai KGH, Liu C. Enhancement of dissolution rate of rofecoxib using solid dispersions with urea. Drug Dev Res. 2004;63(4):181-9.

91. Enose AA, Dasan P, Sivaramakrishanan $\mathrm{H}$, et al. Formulation, characterization and pharmacokinetic evaluation of telmisartan solid dispersions. J Mol Pharm Org Process Res. 2016.

92. Ren Y, Mei L, Zhou L, et al. Recent Perspectives in Hot Melt Extrusion-Based Polymeric Formulations for Drug Delivery: Applications and Innovations. AAPS Pharm Sci Tech. 2019;20(3):92.

93. Maurya D, Belgamwar V, Tekade A. Microwave induced solubility enhancement of poorly water soluble atorvastatin calcium. J Pharm Pharmacol. 2010;62(11):1599-606.

94. Zhang Z, Chen Y, Deng J, et al. Solid dispersion of berberine--phospholipid complex/TPGS 1000/SiO2: Preparation, characterization and in vivo studies. Int J Pharm. 2014;465(1-2):306-16.

95. Sonar PA, Behera AL, Banerjee SK, et al. Preparation and characterization of Simvastatin solid dispersion using skimmed milk. Drug Dev Ind Pharm. 2015;41(1):22-7.

96. Sethia S, Squillante E. Solid dispersion of carbamazepine in PVP K30 by conventional solvent evaporation and supercritical methods. Int $\mathrm{J}$ Pharm. 2004;272(1-2):1-10.

97. Zhou $\mathrm{H}$, Wang $\mathrm{W}, \mathrm{Hu} \mathrm{H}$, et al. Co-precipitation of calcium carbonate and curcumin in an ethanol medium as a novel approach for curcumin dissolution enhancement. J Drug Deliv Sci Technol. 2019;51:397-402.

98. Danjo K, Nakata T, Otsuka A. Preparation and dissolution behavior of ethenzamide solid dispersions using various sugars as dispersion carriers. Chem Pharm Bull. 1997;45(11):1840-4.

99. Zhang Z, Lin L, Tang H, et al. A Convenient Fluorescence-Based Assay for the Detection of Sucrose Transport and the Introduction of a Sucrose Transporter from Potato into Clostridium Strains. Molecules. 2019;24(19):3495.

100. Ohrem HL, Schornick E, Kalivoda A, et al. Why is mannitol becoming more and more popular as a pharmaceutical excipient in solid dosage forms? Pharm Dev Technol. 2014;19(3):257-62.

101. Yuvaraja K, Das SK, Khanam J. Process optimization and characterization of carvedilol solid dispersion with hydroxypropyl- $\beta$-cyclodextrin and tartaric acid. Korean J Chem Eng. 2015;32(1):132-40.

102. Dash RP, Srinivas NR, Babu RJ. Use of sorbitol as pharmaceutical excipient in the present day formulations-issues and challenges for drug absorption and bioavailability. Drug Dev Ind Pharm. 2019;45(9):1421-9.

103. Valizadeh H, Nokhodchi A, Qarakhani N, et al. Physicochemical characterization of solid dispersions of indomethacin with PEG 6000, Myrj 52, lactose, sorbitol, dextrin, and Eudragit $₫$ E100. Drug Dev Ind Pharm. 2004;30(3):303-17.

104. Liu Y, Wang T, Ding W, et al. Dissolution and oral bioavailability enhancement of praziquantel by solid dispersions. Drug Deliv Transl Res. 2018;8(3):580-90.

105. Di Giuseppe E. Analogue Materials in Experimental Tectonics. Journal name???

106. Kumar V, Vishwakarma RA, Bharate SS. Engineering solid dispersions of anticancer preclinical lead, IIIM-985: Physicochemical characterization and in vivo pharmacokinetics. J Drug Deliv Sci Technol. 2019;49:594-602.

107. Huichao W, Shouying D, Yang $L$, et al. The application of biomedical polymer material hydroxy propyl methyl cellulose (HPMC) in pharmaceutical preparations. J Chem Pharm Res. 2014;6(5):155-60.

108. Ohara T, Kitamura S, Kitagawa $\mathrm{T}$, et al. Dissolution mechanism of poorly water-soluble drug from extended release solid dispersion system with ethylcellulose and hydroxypropylmethylcellulose. Int J Pharm. 2005;302(12):95-102. 
109. Maincent J, Williams RO. Sustained-release amorphous solid dispersions. Drug Deliv TransI Res. 2018;8(6):1714-25

110. Basha M, Salama A, Noshi SH. Soluplus ${ }^{\circledR}$ based solid dispersion as fast disintegrating tablets: a combined experimental approach for enhancing the dissolution and antiulcer efficacy of famotidine. Drug Dev Ind Pharm. 2020;46(2):253-63.

111. El-Badry M, Fetih G, Fathy M. Improvement of solubility and dissolution rate of indomethacin by solid dispersions in Gelucire 50/13 and PEG4000. Saudi Pharm J. 2009;17(3):217-25.

112. Dabir PD, Purkar PY. Gelucire: A novel tool in formulation of poorly soluble drugs. World J. Pharm. Res. 2018;7:471-81.

113. Panigrahi KC, Patra CN, Jena GK, et al. Gelucire: A versatile polymer for modified release drug delivery system. Future J Pharm Sci. 2018;4(1):102-8.

114. Guan J, Liu Q, Zhang X, et al. Alginate as a potential diphase solid dispersion carrier with enhanced drug dissolution and improved storage stability. Eur $\mathrm{J}$ Pharm Sci. 2018;114:346-55.
115. Luo C, Wu W, Lou S, et al. Improving the in vivo bioavailability and in vitro anti-inflammatory activity of tanshinone IIA by alginate solid dispersion. J Drug Deliv Sci Technol. 2020;60:101966.

116. Imai $\mathrm{T}$, Shiraishi $\mathrm{S}$, Saitô $\mathrm{H}$, et al. Interaction of indomethacin with low molecular weight chitosan, and improvements of some pharmaceutical properties of indomethacin by low molecular weight chitosans. Int J Pharm. 1991;67(1):11-20.

117. KUMAR SGV, Mishra DN. Preparation and evaluation of solid dispersion of meloxicam with skimmed milk. Yakugaku Zasshi. 2006;126(2):93-7.

118. Rodde MS, Divase GT, Devkar TB, et al. Solubility and bioavailability enhancement of poorly aqueous soluble atorvastatin: in vitro, ex vivo, and in vivo studies. Bio Med Res Int. 2014.

119. Nagpal M, Aggarwal G, Sharma P, et al. Neem Gum Based Solid Dispersion in Development of Aceclofenac Tablet with Enhanced Bioavailability. Drug Deliv Lett. 2017;7(2):115-24.

120. Anamika S, Shikha A. Solubility enhancement potential of tamarind seed polysaccharide as pharmaceutical excipient. Int J Pharm Biol Arch. 2012;3(3):456-9.

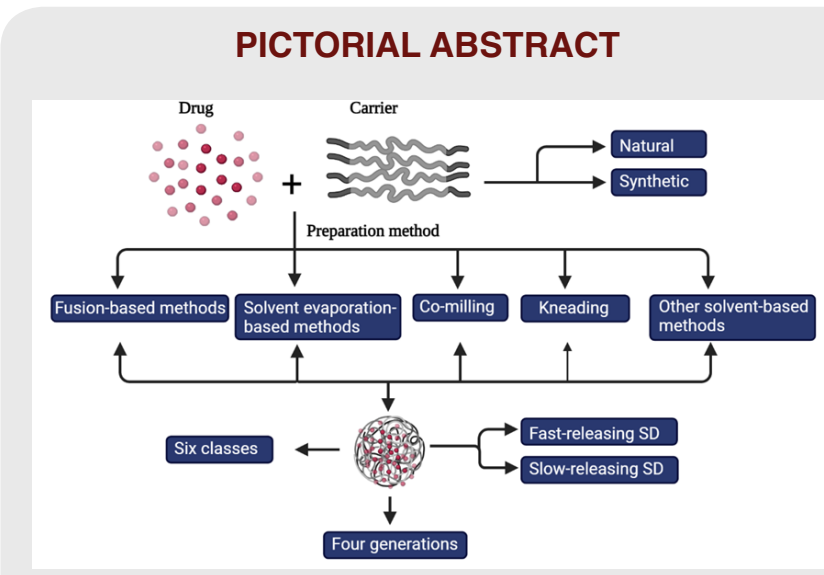

\section{SUMMARY}

- Many of the currently marketed drugs suffer from poor water solubility and decreased oral bioavailability.

- Several pharmaceutical strategies were proposed, including solid dispersion as a straightforward technique to overcome the addressed issue of poor water solubility.

- The first part of the review discusses the classification of solid dispersion according to their recent advances and the nature of drug dispersion into the carrier

- The second part focused on the available preparation methods and their development in the up-to-date literature.

- The last part covered the different classes of solid dispersion carriers, including synthetic and natural ones.

\footnotetext{
About Authors

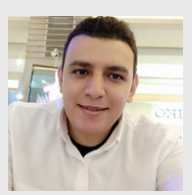

Mohamed S. Attia, is a Master's student and Teaching Assistant at the Faculty of Pharmacy, Zagazig University, where he graduated with a Bachelor of Pharmacy. His Master's thesis focuses on the enhancement of dissolution rate and bioavailability of poorly water-soluble drugs. He is currently working as a research assistant at the Applied Nucleic Acid Research Center (ANARC).

Azza Ali Hasan, is an Assistant Professor of Pharmaceutics at the Faculty of Pharmacy at Zagazig University, where she was graduated and continued his postgraduate studies. Her Master's thesis was a pharmaceutical study of certain non-narcotic analgesics, while her ph.d. thesis focused on the formulation and evaluation of certain controlled release drug delivery systems. She worked as a Lecturer at the College of Clinical Pharmacy, King Faisal University, from 2008 to 2013.
} 
Fakhr-Eldin S. Ghazy, is an Emeritus Professor of Pharmaceutics at the Faculty of Pharmacy at Zagazig University. His Ph.D. degree in the Pharmaceutical Sciences (1978); Kyoto University, Kyoto; Japan was entitled: the effect of riboflavin photosynthetic products on the absorption of some drugs in mice. Consultant for Alkahira Pharmaceutical Compy, Cairo, Egypt from 1990 to 2005. He worked as a consultant for Misr Pharmaceutical Compy; Cairo; Egypt from 1985 to 2005. Also, worked as a consultant for the National Organization for Drug Control and Research; Giza; Egypt from 1981 to 1986 . He is a member of the Scientific Committee for Assistant Professors and Professors; Faculty of Pharmacy; Alazhar University, Cairo; Egypt since 2012 till now.

Eman Gomaa, is a Lecturer of Pharmaceutics at the Faculty of Pharmacy at Zagazig University, where she was graduated and continued his postgraduate studies. Her Master's thesis was about the Formulation and evaluation of antihypertensive drugs following rectal administration, while her Ph.D. thesis focused on the relationship between pharmaceutical formulations of specific drugs and their bioavailability.

Cite this article: Attia MS, Hasan AA, Ghazy FES, Gomaa E. Solid Dispersion as a Technical Solution to Boost the Dissolution Rate and Bioavailability of Poorly Water-Soluble Drugs. Indian J of Pharmaceutical Education and Research. 2021;55(2s):s327-s339. 